\title{
XRCC1 and XPD polymorphisms and their relation to the clinical course in hepatocarcinoma patients
}

\author{
QINGHAI GUAN ${ }^{1,2}$, ZHIQIANG CHEN $^{1}$, QIANGPU CHEN $^{2}$ and XUTING ZHI ${ }^{1}$ \\ ${ }^{1}$ Department of General Surgery, Qilu Hospital, Shandong University, Jinan, Shandong 250012; ${ }^{2}$ Department of \\ General Surgery, The Affiliated Hospital of Binzhou Medical College, Binzhou, Shandong 256603, P.R. China
}

Received March 16, 2017; Accepted June 29, 2017

DOI: $10.3892 / 01.2017 .6522$

\begin{abstract}
In this study genotyping of hepatocellular carcinoma (HCC) patients was conducted to detect polymorphisms on the X-ray repair cross-complementing 1 (XRCC1) and xeroderma pigmentosum complementary group D (XPD) genes and analyze the relationship of their presence with the clinical features of the cancer. A total of 172 patients with HCC were selected in Qilu Hospital, Shandong University, from January 2010 to September 2011. All patients underwent resection of HCC and no tumor metastases were found. Peripheral venous blood samples $(3-5 \mathrm{ml})$ were collected from the patients to extract genomic DNA. Genotyping was performed by polymerase chain reaction-restriction fragment length polymorphism (PCR-RFLP) and gene sequencing. During the five-year follow-up, the survival of patients with various genotypes of XRCC1 and XPD genes were observed and compared. Logistic regression analysis was used to analyze the association between single nucleotide polymorphisms of XRCC1 and XPD genes and the prognosis of patients with HCC. $\chi^{2}$ tests showed that XRCC1-194, XRCC1280 and XPD-312 gene polymorphisms were significantly correlated with the number, location and diameter of the tumors $(\mathrm{p}<0.05)$. No significant difference was found in the survival curve of patients presenting different genotypes of the XRCC1-194 locus ( $>00.05$ ). Nevertheless, a significant difference was found in the survival curve of patients with AA and GG genotypes of the XRCC1-280 locus and in the patients with AA, GA and GG genotypes of the XPD-312 locus $(\mathrm{p}<0.05)$. Logistic regression analysis showed that the XRCC1-194 genotype was not an independent risk factor for HCC mortality risk ( $>0.05)$, but XRCC1-280 $(\mathrm{OR}=1.815$, $\mathrm{p}<0.01)$ and $\mathrm{XPD}-312(\mathrm{OR}=1.815, \mathrm{p}<0.01)$ genotypes were
\end{abstract}

Correspondence to: Professor Xuting Zhi, Department of General Surgery, Qilu Hospital, Shandong University, 107 Wenhuaxi Road, Jinan, Shandong 250012, P.R. China

E-mail: zhixuting@hotmail.com

Key words: hepatocellular carcinoma, X-ray repair crosscomplementing 1, xeroderma pigmentosum complementary group D, prognosis independent risk factors for a poor prognosis. Taken together our results point to polymorphisms in XRCC1 and XPD genes as being related to the clinical characteristics of HCC, making them suitable prognostic markers of HCC.

\section{Introduction}

Primary liver cancer is one of the most common malignant tumors, and hepatocellular carcinoma (HCC) is the main type (1). HCC is the result of a complex pathological process involving multiple factors that has an insidious onset, rapid progress and high mortality rates. The 5 -year survival rate is $<10 \%$ (2). HCC mainly affects people between 40 and 50 years of age, but the age of presentation has gradually been shifting to a younger population; the incidence in males is higher than in females (3). DNA damage can be caused by various factors. The accumulation of DNA damage and errors occurring during DNA repair can eventually lead to cell carcinogenesis (4). DNA repair genes include X-ray repair cross-complementing 1 (XRCC1) and xeroderma pigmentosum complementary group D (XPD). Genetic polymorphisms in those genes and the resulting specific interactions of their products are a recognized basis for the occurrence of HCC. The determination of genetic polymorphisms of those genes can be helpful for treatment and prognosis of certain cancers $(5,6)$. In this study, XRCC1-194, XRCC1-280 and XPD-312 gene polymorphisms in liver cancer patients were detected in order to provide a theoretical basis for the treatment and prognosis of the disease.

\section{Materials and methods}

General information. A total of 172 patients with HCC in Qilu Hospital, Shandong University, were enrolled in the study from January 2010 to September 2011. All the patients in the study had been diagnosed with HCC by liver biopsy and imaging examination according to the diagnostic criteria established by the American Association for the Study of Liver Diseases (AASLD); the patients received radical treatment and signed the informed consent form.

Patients with severe dysfunctions of the heart, brain, lung, kidney or other organs and patients presenting mental or neurological disorders or other diseases were excluded from the study. There were a total of 121 males and 51 females. 
Table I. Primer sequences for XRCC1 and XPD.

\begin{tabular}{lll}
$\begin{array}{l}\text { Microsatellite } \\
\text { loci }\end{array}$ & \multicolumn{1}{c}{ Sequences } & Length \\
\hline XRCC1-194 & F: 5'-CTGACCTTGCGGGACCTTA-3' & 455 bp \\
& R: 5'-GTCGCTGGCTGTGACTATG-3' & \\
XRCC1-280 & F: 5'-CCCCAGTGGTGCTAACCTAA-3' 304 bp \\
& R: 5'-CTACATGAGGTGCGTGCTGT-3' \\
XPD-312 & F: 5'-CTGTTGGTGGGTGCCCGTATC & \\
& TGTTGGTCT-3' & \\
& R: 5'-TAATATCGGGGCTCACCCTG & \\
& CAGCACTTCCT-3' &
\end{tabular}

F, forward; R, reverse; XRCC1, X-ray repair cross-complementing 1; $\mathrm{XPD}$, xeroderma pigmentosum complementary group $\mathrm{D}$.

The age of the patients ranged from 40 to 70 years with a mean age of $50.36 \pm 4.78$ years. The patients were classified according to the diameter of their tumor: There were 80 cases with diameters smaller than $5 \mathrm{~cm}, 76$ with diameters from 5 to $10 \mathrm{~cm}$ and 16 with diameters larger than $10 \mathrm{~cm}$. Also, according to the number of tumors present in each patient, 145 cases had a single tumor and 27 cases presented multiple tumors. In 79 cases the tumors were found in the left lobe, in 69 cases the tumors were in the right lobe and in 24 cases in other positions. This study was approved by the Ethics Committee of Qilu Hospital. Signed written informed consents were obtained from the patients.

Epidemiological survey. The patient's demographic characteristics were investigated and their medical records and physical examination results were collected to establish a research database for statistical analyses. Five-year follow-up was conducted and the data collected was used in this study.

Sample collection. Peripheral blood samples $(3-5 \mathrm{ml})$ were collected after fasting for $8 \mathrm{~h}$. The samples were transferred to blood collection tubes containing ethylenediaminetetraacetic acid. The tubes were numbered and stored at $-20^{\circ} \mathrm{C}$.

XRCC1 and XPD gene detection. Blood genomic DNA extraction from the samples was performed according to the instructions of DNA extraction kit (Promega, Madison, WI, USA). The primers for PCR were synthesized at Shanghai Boa Biotechnology (Shanghai, China) and the sequences are listed in Table I. The PCR amplification procedures followed the instructions in the One-Step qRT-PCR kit (Invitrogen, Carlsbad, CA, USA). The protocol for the amplification of the XRCC1-194 locus gene included an initial $95^{\circ} \mathrm{C}$ for 5 min step, followed by 35 cycles of $94^{\circ} \mathrm{C}$ for $30 \mathrm{sec}, 57^{\circ} \mathrm{C}$ for $30 \mathrm{sec}$ and $72^{\circ} \mathrm{C}$ for $45 \mathrm{sec}$ and then a final step of $72^{\circ} \mathrm{C}$ for $10 \mathrm{~min}$. The protocol for the XRCC1-280 locus gene included an initial step of $95^{\circ} \mathrm{C}$ for $5 \mathrm{~min}$, followed by 35 cycles of $94^{\circ} \mathrm{C}$ for $30 \mathrm{sec}, 62^{\circ} \mathrm{C}$ for $30 \mathrm{sec}$ and $72^{\circ} \mathrm{C}$ for $45 \mathrm{sec}$, with a final step of $72^{\circ} \mathrm{C}$ for $7 \mathrm{~min}$. PCR products were analyzed by agarose gel electrophoresis (Six One Instrument Factory, Beijing, China). Briefly, a 2.0\% agarose gel was prepared, containing nucleic acid dye, the solid gel was placed in a horizontal electrophoresis tank containing electrophoresis buffer. A $5 \mu 1$ PCR product sample was mixed with loading buffer and the mixture was subjected to electrophoresis at $100 \mathrm{~V}$ for $30 \mathrm{~min}$. The gel was then observed under an ultraviolet transmittance analyzer and images were saved.

PCR products were sequenced using reagents from $A B I$ (Applied Biosystems, Grand Island, NY, USA). Briefly, PCR product $(1 \mu 1)$ was mixed with $2 \mu 1$ SAP MIX for digestion in a thermocycler (Wenzhou Yongqiang medical equipment, Zhejiang, China). PCR digestion products, sequencing reagents and sequencing primers were mixed and the PCR amplification was performed. The sequencing amplification product was mixed with a sodium acetate-ethanol solution and centrifuged to remove the supernatant. A DNA dissolving solution was added. The purified DNA was then subjected to electrophoresis with a DNA sequencer.

Statistical analysis. Data were processed using SPSS 19.0 software (SPSS Inc., Chicago, IL, USA). Countable data were expressed by number of cases and the composition ratio. The relationship between different genotypes and the clinical features of HCC was examined using the $\chi^{2}$ test. Logistic regression analysis was used to analyze the prognostic factors of HCC. The Kaplan-Meier survival analysis was also performed. P-value $<0.05$ were considered to indicate a statistically significant difference.

\section{Results}

Allele frequency and genotype distribution of XRCC1 and $X P D$ loci. The allele frequencies for CC, CT and TT genotypes of the XRCC1-194 locus, AA and GG genotypes of the XRCC1-280 locus and AA, GA and GG genotypes of the XPD-312 locus found in the population of patients are listed in Table II.

Analysis of the relationship between XRCC1-194, XRCC1-280 and XPD-312 gene polymorphisms and the clinical characteristics of HCC. XRCC1-194, XRCC1-280 and XPD-312 gene polymorphisms were significantly correlated with tumor number, tumor location and tumor diameter $(\mathrm{p}<0.05)$, but were not correlated with capsule invasion or the general type of cancer ( $p>0.05$ ) (Tables III-V).

Genotypes and survival of patients. No significant differences were found in the survival curves of patients with CC, CT or TT genotypes of the XRCC1-194 locus ( $\mathrm{p}>0.05$ ). Nevertheless, the survival curves of patients with AA and GG genotypes at the XRCC1-280 locus and those in patients with AA, GA and GG genotypes at the XPD-312 locus differed significantly $(\mathrm{p}<0.05)$ (Figs. 1-3).

The influencing factors of HCC prognosis. The risk of poor prognosis in patients with $\mathrm{HCC}$ was set as a dependent variable; and factors such as age, sex, educational level, living status and XRCC1-194, XRCC1-280 and XPD-312 genotypes were set as independent variables. Logistic regression 
Table II. Allele frequency and genotype distribution for XRCC1 and XPD loci in HCC patients (n, \%).

\begin{tabular}{llcccc}
\hline XRCC1-194 & Frequency & XRCC1-280 & Frequency & XPD-312 & Frequency \\
\hline CC & $95(55.23)$ & AA & $35(20.35)$ & AA & $29(16.86)$ \\
CT & $13(7.56)$ & - & - & GA & $15(8.72)$ \\
TT & $64(37.21)$ & GG & $137(79.65)$ & GG & $128(74.42)$ \\
\hline
\end{tabular}

XRCC1, X-ray repair cross-complementing 1; XPD, xeroderma pigmentosum complementary group D; HCC, hepatocellular carcinoma.

Table III. Relationship between XRCC1-194 gene polymorphism and clinical characteristics of HCC.

\begin{tabular}{|c|c|c|c|c|c|}
\hline \multirow[b]{2}{*}{ Clinical features } & \multicolumn{3}{|c|}{ XRCC1-194 (n, \%) } & \multirow[b]{2}{*}{$\chi^{2}$} & \multirow[b]{2}{*}{ P-value } \\
\hline & $\mathrm{CC}$ & $\mathrm{CT}$ & $\mathrm{TT}$ & & \\
\hline General types & & & & 0.653 & 0.957 \\
\hline Giant block type & $30(54.55)$ & $4(7.27)$ & $21(38.18)$ & & \\
\hline Nodular type & $27(54.00)$ & $3(6.00)$ & $20(40.00)$ & & \\
\hline Diffuse type & $38(56.72)$ & $6(8.96)$ & $23(34.33)$ & & \\
\hline No. of tumors & & & & 8.621 & 0.013 \\
\hline Single tumor & $83(57.24)$ & $7(4.83)$ & $55(37.93)$ & & \\
\hline Multiple tumors & $12(44.44)$ & $6(22.22)$ & $9(33.33)$ & & \\
\hline Liver tumor location & & & & 10.149 & 0.038 \\
\hline Left lobe & $42(53.16)$ & $5(6.33)$ & $32(40.51)$ & & \\
\hline Right lobe & $38(55.07)$ & $3(4.35)$ & $28(40.58)$ & & \\
\hline Other & $15(62.50)$ & $5(20.83)$ & 4 (16.67) & & \\
\hline Tumor diameter & & & & 10.432 & 0.034 \\
\hline$<5 \mathrm{~cm}$ & $42(52.50)$ & $5(6.25)$ & $33(41.25)$ & & \\
\hline $5-10 \mathrm{~cm}$ & $43(56.58)$ & $4(5.26)$ & $29(38.16)$ & & \\
\hline$>10 \mathrm{~cm}$ & $10(62.50)$ & $4(25.00)$ & $2(12.50)$ & & \\
\hline Capsule invasion & & & & 2.239 & 0.327 \\
\hline Yes & $32(53.33)$ & $7(11.67)$ & $21(35.00)$ & & \\
\hline No & $63(56.25)$ & $6(5.36)$ & 43 (38.39) & & \\
\hline
\end{tabular}

XRCC1, X-ray repair cross-complementing 1; HCC, hepatocellular carcinoma.

analysis showed that age, sex, educational level, living status and XRCC1-194 genotype $(\mathrm{OR}=0.945, \mathrm{p}=0.734)$ were not independent risk factors for a poor HCC prognosis, but $\mathrm{XRCC} 1-280(\mathrm{OR}=1.323, \mathrm{p}=0.006)$ and XPD-312 $(\mathrm{OR}=1.815$, $\mathrm{p}=0.008)$ genotypes were independent risk factors for poor HCC prognosis $(\mathrm{p}<0.05)$ (Table VI).

\section{Discussion}

Liver cancer often arises in hepatocytes or intrahepatic bile duct cells, HCC and intrahepatic cholangiocarcinoma are the most common types of liver cancer. HCC accounts for more than $80 \%$ of liver cancers, and its incidence and mortality rate both rank in the first three positions among all the malignant tumors (3). The clinical manifestations of HCC include flank pain, loss of appetite, weight loss, ascites and jaundice, and even coma and systemic failure $(7,8)$. The pathogenesis of
HCC is complex; it involves a dynamic process of long-term accumulation of the actions of multiple different factors including the presence of genetic polymorphism and environmental factors (9). At present, treatment outcomes of HCC are not satisfactory. Radical resection is the main treatment method, but the recurrence rate after the procedure is still high (10). A better understanding of the genetic underlying genetic mechanisms will aid in the development of improved treatment strategies.

Genetic polymorphisms are usually classified into one of three categories: Fragment length polymorphisms (FLPs), repeated sequence polymorphisms (RSPs) and single nucleotide polymorphisms (SNPs) (11). Genetic polymorphisms may affect the protein expression, or the composition of cytokine molecules leading to different clinical presentations, and different prognoses for HCC (12). DNA repair systems play important roles in the normal regulation of the cell cycle and 
Table IV. Relationship between XRCC1-280 gene polymorphism and clinical characteristics of HCC.

\begin{tabular}{lrrrr}
\hline & \multicolumn{2}{c}{ XRCC1-280(n, \%) } & & \\
\cline { 2 - 3 } Clinical features & AA & GG & \multirow{2}{*}{$\chi^{2}$} & P-value \\
\hline General typing & & & 5.095 & 0.078 \\
Giant block type & $13(23.64)$ & $42(76.36)$ & & \\
Nodular type & $14(28.00)$ & $36(72.00)$ & & \\
Diffuse type & $8(11.94)$ & $59(88.06)$ & & \\
No. of tumors & & & 6.792 & 0.009 \\
Single tumor & $24(16.55)$ & $121(83.45)$ & & \\
Multiple tumors & $11(40.74)$ & $16(59.26)$ & & \\
Tumor location & & & 10.902 & 0.004 \\
in the liver & & & & \\
Left lobe & $15(18.99)$ & $64(81.01)$ & & \\
Right lobe & $10(14.49)$ & $59(85.51)$ & & \\
Other & $11(45.83)$ & $13(54.17)$ & & \\
Tumor diameter & & & 11.238 & 0.003 \\
$<5 \mathrm{~cm}$ & $15(18.75)$ & $65(81.25)$ & & \\
$5-10 \mathrm{~cm}$ & $12(15.79)$ & $64(84.21)$ & & \\
$>10 \mathrm{~cm}$ & $8(50.00)$ & $8(50.00)$ & & \\
Capsule invasion & & & 2.907 & 0.088 \\
Yes & $17(28.33)$ & $43(71.67)$ & & \\
No & $18(16.07)$ & $94(83.93)$ & & \\
\hline
\end{tabular}

XRCC1, X-ray repair cross-complementing 1; HCC, hepatocellular carcinoma.

maintenance of cell integrity, and are essential body's defense mechanisms against tumors. Altered DNA repair systems lead to the accumulation of gene mutations in the human genome and can result in the development of cancers (13). About 90\% of mutations in the human genome are caused by SNPs, and studies have confirmed that gene mutations can lead to different repair capabilities that can result in tumor malignancies (14). Ionizing radiation, ultraviolet light and a variety of chemical factors can lead to DNA single and double strand breaks, DNA protein cross-linking, base mismatch and other genetic damage. The gene repair system can effectively repair these DNA mistakes, maintaining the stability of the genetic information. The known repair genes include hMSH2, XPD, XRCC1, hOGG1 and XRCC3 $(15,16)$.

The length of the XRCC1 gene is $\sim 32 \mathrm{~kb}$. The XRCC1 gene contains 17 exons and 60 SNP loci; it participates in DNA damage repair, cell cycle and DNA transcription regulation (17). The product of XRCC1 can combine with DNA ligase III, DNA polymerase $\beta$ and polysaccharide enzyme to form a complex, which repairs single-stranded DNA mistakes. This complex can also act as a protein scaffold to stablize the DNA structure (18). The results of our study show that the XRCC1-194 alleles CC and TT were mostly found in patients with a single tumor in the left lobe of the liver and a tumor diameter smaller than $10 \mathrm{~cm}$. On the other hand, the XRCC1-280 GG allele was mostly found in patients exhibiting

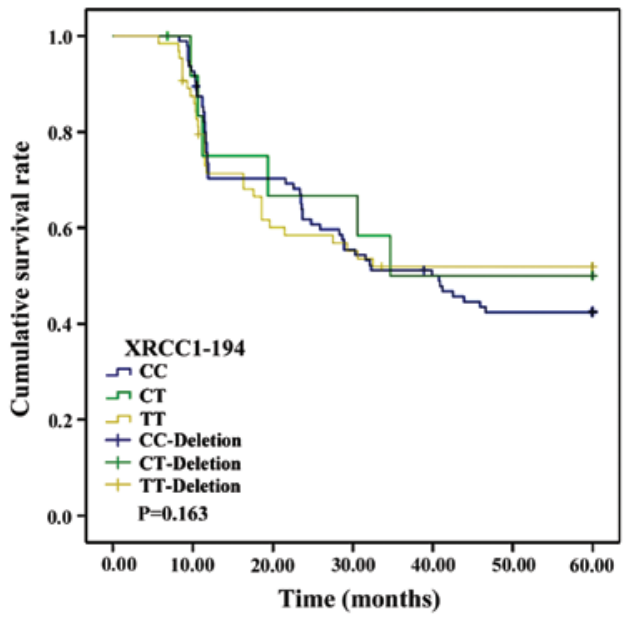

Figure 1. Survival curve of patients with XRCC1-194 loci polymorphism. Kaplan-Meier analysis showed no significant correlation between XRCC1-194 loci polymorphism and the survival of the patients $(\mathrm{p}>0.05)$. XRCC1, X-ray repair cross-complementing 1 .

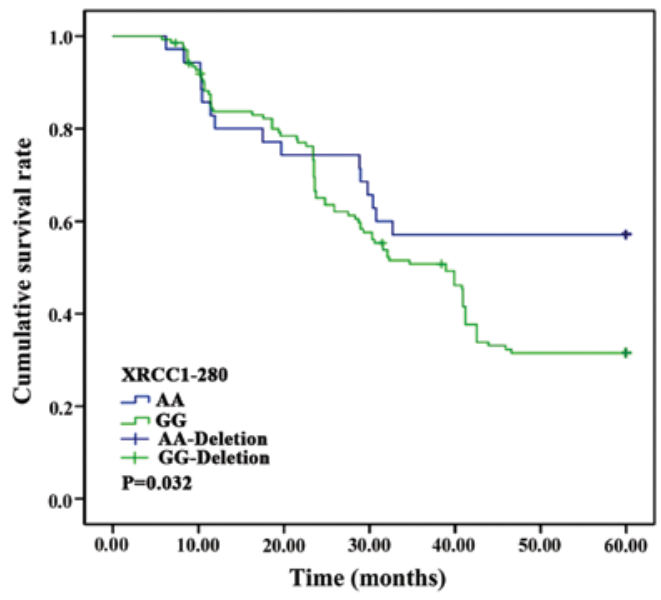

Figure 2. Survival curve of patients with XRCC1-280 loci polymorphism. Kaplan-Meier analysis showed significant correlation between XRCC1-280 loci polymorphism and the survival of the patients $(\mathrm{p}<0.05)$. XRCC1, X-ray repair cross-complementing 1 .

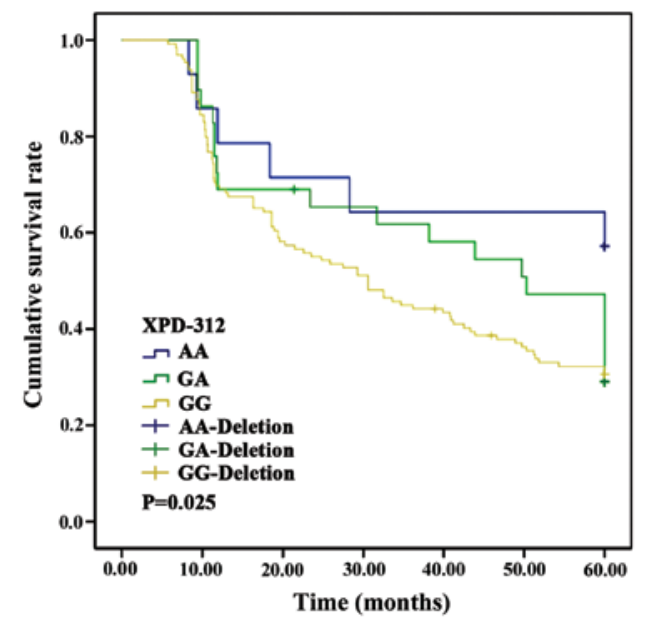

Figure 3. Survival curve of patients with XPD-312 loci polymorphism. Kaplan-Meier analysis showed significant correlation between XPD-312 loci polymorphism and the survival of the patients $(\mathrm{p}<0.05)$. XPD, xeroderma pigmentosum complementary group $\mathrm{D}$. 
Table V. Relationship between XPD-312 gene polymorphism and clinical characteristics of HCC.

\begin{tabular}{|c|c|c|c|c|c|}
\hline \multirow[b]{2}{*}{ Clinical features } & \multicolumn{3}{|c|}{ XPD-312 (n, \%) } & \multirow[b]{2}{*}{$\chi^{2}$} & \multirow[b]{2}{*}{ P-value } \\
\hline & AA & GA & GG & & \\
\hline General typing & & & & 2.507 & 0.643 \\
\hline Giant block type & $10(18.18)$ & $4(7.27)$ & $41(74.55)$ & & \\
\hline Nodular type & $11(22.00)$ & $5(10.00)$ & $34(68.00)$ & & \\
\hline Diffuse type & $18(11.94)$ & $6(8.96)$ & $52(79.10)$ & & \\
\hline No. of tumors & & & & 19.309 & $<0.001$ \\
\hline Single tumor & $19(13.10)$ & $9(6.21)$ & $117(80.69)$ & & \\
\hline Multiple tumors & $10(37.04)$ & $6(22.22)$ & $11(40.74)$ & & \\
\hline Liver tumor location & & & & 11.831 & 0.019 \\
\hline Left lobe & $12(15.19)$ & $5(6.33)$ & $62(78.48)$ & & \\
\hline Right lobe & $11(15.94)$ & $4(5.80)$ & $54(78.26)$ & & \\
\hline Other & $6(25.00)$ & $6(25.00)$ & $12(50.00)$ & & \\
\hline Tumor diameter & & & & 19.502 & $<0.001$ \\
\hline$<5 \mathrm{~cm}$ & $11(13.75)$ & $4(5.00)$ & $65(81.25)$ & & \\
\hline $5-10 \mathrm{~cm}$ & $13(17.11)$ & $6(7.89)$ & $57(75.00)$ & & \\
\hline$>10 \mathrm{~cm}$ & $6(37.50)$ & $5(31.25)$ & $5(31.25)$ & & \\
\hline Capsule invasion & & & & 2.825 & 0.243 \\
\hline Yes & $11(18.33)$ & $8(13.33)$ & $41(68.33)$ & & \\
\hline No & $18(16.07)$ & $7(6.25)$ & $87(77.68)$ & & \\
\hline
\end{tabular}

XPD, xeroderma pigmentosum complementary group D; HCC, hepatocellular carcinoma.

Table VI. Logistic regression analysis of poor prognosis factors for HCC.

\begin{tabular}{lccccr}
\hline Factors & $\beta$ & SE & Wald & OR & 95\% CI \\
\hline Age (years) & 0.331 & 0.512 & 3.783 & 0.631 & $0.375-0.952$ \\
Sex & 0.437 & 0.517 & 6.372 & 0.215 & $0.104-0.779$ \\
Educational level & -0.467 & 0.673 & 5.321 & 0.013 & $0.456-0.854$ \\
Living status & -0.635 & 0.814 & 6.425 & 0.217 & $0.196-0.542$ \\
XRCC1-280 & 1.426 & 0.749 & 7.757 & 1.323 & $1.075-2.252$ \\
XPD-312 & 1.433 & 0.517 & 4.524 & 1.815 & 0.309 \\
XRCC1-194 & 0.815 & 0.426 & 5.232 & 0.945 & 0.153 \\
& & & & $0.625-0.973$ & 0.006 \\
\end{tabular}

HCC, hepatocellular carcinoma; XRCC1, X-ray repair cross-complementing 1; XPD, xeroderma pigmentosum complementary group D; $\mathrm{CI}$, confidence interval.

a single left lobe tumor with a diameter smaller than $10 \mathrm{~cm}$. Additionally, the XRCC1-194 and XRCC1-280 gene polymorphisms were significantly correlated with tumor number, location and diameter $(\mathrm{p}<0.05)$, indicating that the polymorphisms can be used as markers predicting biological behavior of HCC.

The XPD gene, another DNA repair gene, contains 23 exons and 6 SNP sites. The main function of XPD is nucleotide excision (19). However, XPD can also participate in p53-mediated apoptosis and in transcription by being part of the transcription factor II D (TFIID) (20). A single base mutation in XPD can cause a change in the protein function, and lead to tumorigenesis (21). The results of this study show that XPD-312 AA and GG were mostly found in patients with single tumors $(<10 \mathrm{~cm}$ in diameter) in the left lobe of HCC patients. The XPD-312 gene polymorphism was significantly correlated with tumor number, location and diameter $(\mathrm{p}<0.05)$. This probably means the XPD-312 SNP can alter the ability of its cognate protein to participate in repair, ultimately promoting the progress of HCC.

Due to the rapid growth of liver tumors, and their vascular invasion, capsule infiltration and distant metastases, the prognosis in $\mathrm{HCC}$ is extremely poor. Our study found no significant differences in the survival curves between the patients with CC, CT and TT genotypes of the XRCC1-194 locus ( $p>0.05$ ). However, a significant difference was found in the survival 
curve of patients with AA and those with GG genotypes of the XRCC1-280 locus; and in the patients with AA, GA and GG genotypes of the XPD-312 locus $(\mathrm{p}<0.05)$. Logistic regression analysis showed that the OR of RCC1-194 genotype is 0.945 , the OR of XRCC1-280 is 1.323 and the OR of XPD-312 is 1.815. Therefore, we think it is possible that XRCC1-280 and XPD-312 may be involved in promoting the development of HCC, shortening the time of recurrence and metastasis, and negatively affecting the overall survival of patients. We are aware of the small population size of our study and know that additional studies are needed in order to confirm our findings. Nevertheless, the evidence strongly suggests that XRCC1-280 and XPD-312 loci should be useful as reference markers for predicting the evolution of the disease in HCC patients.

\section{References}

1. Bruix J, Gores GJ and Mazzaferro V: Hepatocellular carcinoma: Clinical frontiers and perspectives. Gut 63: 844-855, 2014.

2. Lee SS, Shin HS, Kim HJ, Lee SJ, Lee HS, Hyun KH, Kim YH, Kwon BW, Han JH, Choi $\mathrm{H}$, et al: Analysis of prognostic factors and 5-year survival rate in patients with hepatocellular carcinoma: A single-center experience. Korean J Hepatol 18: $48-55,2012$.

3. Kew MC: Hepatocellular carcinoma: Epidemiology and risk factors. J Hepatocell Carcinoma 1: 115-125, 2014.

4. Seguí N, Mina LB, Lázaro C, Sanz-Pamplona R, Pons T, Navarro M, Bellido F, López-Doriga A, Valdés-Mas R, Pineda M, et al: Germline mutations in FAN1 cause hereditary colorectal cancer by impairing DNA repair. Gastroenterology 149: 563-566, 2015.

5. Patrono C, Sterpone S, Testa A, Verna L, Palma V, Gentile P and Cozzi R: Polymorphisms in X-ray repair cross-complementing group 1 gene: Haplotypes, breast cancer risk and individual radiosensitivity. Open Med J 2: 25-30, 2015.

6. Tamura D, DiGiovanna JJ, Khan SG and Kraemer KH: Living with xeroderma pigmentosum: Comprehensive photoprotection for highly photosensitive patients. Photodermatol Photoimmunol Photomed 30: 146-152, 2014

7. Wang YX, De Baere T, Idee JM and Ballet S: Transcatheter embolization therapy in liver cancer: An update of clinical evidences. Chin J Cancer Res 27: 96-121, 2015.

8. Hung HH, Chao Y, Chiou YY, Li CP, Lee RC, Huo TI, Huang YH, Chau GY, Su CW, Yeh YC, et al: A comparison of clinical manifestations and prognoses between patients with hepatocellular carcinoma and Child-Pugh scores of 5 or 6 . Medicine (Baltimore) 93: e348, 2014.
9. Liu F, Wang J, Chang H, Lu J and Li H: Relevance between HLA-DP gene rs2281388 polymorphism and hepatocellular carcinoma risk. Int J Clin Exp Pathol 8: 7431-7435, 2015.

10. Huang X, Zeng Y, Xing X, Zeng J, Gao Y, Cai Z, Xu B, Liu X, Huang A and Liu J: Quantitative proteomics analysis of early recurrence/metastasis of huge hepatocellular carcinoma following radical resection. Proteome Sci 12: 22, 2014.

11. Petta S, Miele L, Bugianesi E, Cammà C, Rosso C, Boccia S, Cabibi D, Di Marco V, Grimaudo S, Grieco A, et al: Glucokinase regulatory protein gene polymorphism affects liver fibrosis in non-alcoholic fatty liver disease. PLoS One 9: e87523, 2014.

12. Akhdar H, El Shamieh S, Musso O, Désert R, Joumaa W, Guyader D, Aninat C, Corlu A and Morel F: The rs3957357C > T SNP in GSTA1 is associated with a higher risk of occurrence of hepatocellular carcinoma in european individuals. PLoS One 11: e0167543, 2016.

13. Duxin JP and Walter JC: What is the DNA repair defect underlying Fanconi anemia? Curr Opin Cell Biol 37: 49-60, 2015.

14. Bharati R, Jenkins MA, Lindor NM, Le Marchand L, Gallinger S, Haile RW, Newcomb PA, Hopper JL and Win AK: Does risk of endometrial cancer for women without a germline mutation in a DNA mismatch repair gene depend on family history of endometrial cancer or colorectal cancer? Gynecol Oncol 133: 287-292, 2014.

15. Caldecott KW: DNA single-strand break repair. Exp Cell Res 329: 2-8, 2014.

16. Adel Fahmideh M, Schwartzbaum J, Frumento $\mathrm{P}$ and Feychting M: Association between DNA repair gene polymorphisms and risk of glioma: A systematic review and meta-analysis. Neuro Oncol 16: 807-814, 2014.

17. Wang JY and Cai Y: X-ray repair cross-complementing group 1 codon 399 polymorphism and lung cancer risk: An updated meta-analysis. Tumour Biol 35: 411-418, 2014.

18. Li Y, Ma QH, Huang ZY, Li SW, Liu F and Tan S: P0163 X-ray repair cross-complementing group 1 (XRCC1) genetic polymorphisms and cervical cancer risk: A systematic review and meta-analysis. Eur J Cancer 50: e55, 2014.

19. Liu J, Fang H, Chi Z, Wu Z, Wei D, Mo D, Niu K, Balajee AS, Hei TK, Nie L, et al: XPD localizes in mitochondria and protects the mitochondrial genome from oxidative DNA damage. Nucleic Acids Res 43: 5476-5488, 2015.

20. Bănescu C, Trifa AP, Demian S, Benedek Lazar E, Dima D, Duicu C and Dobreanu M: Polymorphism of XRCC1, XRCC3, and XPD genes and risk of chronic myeloid leukemia. BioMed Res Int 2014: 213790, 2014.

21. Li P, Wang YD, Cheng J, Chen JC and Ha MW: Association between polymorphisms of BAG-1 and XPD and chemotherapy sensitivity in advanced non-small-cell lung cancer patients treated with vinorelbine combined cisplatin regimen. Tumour Biol 36: 9465-9473, 2015. 